\title{
Effects of leisure activities and psychosocial support on medication adherence and clinic attendance among children on antiretroviral therapy
}

This article was published in the following Dove Press journal:

HIVIAIDS - Research and Palliative Care

30 August 2014

Number of times this article has been viewed

\author{
Emmanuel Adémólá \\ Anígilájél \\ Othniel Joseph Dabit \\ Ruth Kashimana Tyovenda ${ }^{2}$ \\ Agnes Jane Emebolu² \\ Augustine Aondohemba \\ Agbedeh ${ }^{2}$ \\ Ayodotun Olutola ${ }^{3}$ \\ Omolara Olufunmilayo \\ Anígilájé ${ }^{4}$ \\ 'Department of Paediatrics, Benue \\ State University, ${ }^{2}$ Department of \\ Paediatrics, Federal Medical Centre, \\ Makurdi, Benue State, ${ }^{3}$ Centre for \\ Clinical Care and Clinical Research, \\ Maitama, Abuja, ${ }^{4}$ Department of Family \\ Medicine, Federal Medical Centre, \\ Makurdi, Benue State, Nigeria
}

Correspondence: Emmanuel Adémólá Anígilájé

Department of Paediatrics, Benue State University, Makurdi, Benue State, Nigeria Tel +2348033833839

Email demolaanigilaje@yahoo.co.uk
Background: Optimal adherence to antiretroviral therapy (ART) and retention-in-care are essential in HIV management. Through a Kiddies' Club (KC), the study aimed at assessing the impact of social leisures and psychosocial support on ART adherence and clinic attendance in a pediatric ART program.

Methods: This was a descriptive, longitudinal study, conducted at the Federal Medical Centre, Makurdi, Nigeria, from June 2011 to June 2012. It included 33 ART-experienced children and their caregivers. The study was supplemented with a qualitative focused group discussion, involving 12 discussants. ART adherence, clinic attendance, and clinical and immunoviralogical responses of the children to ART were noted at 6 months and at 12 months of follow-up.

Results: The children comprised 17 males and 16 females, with a median age of 5 years. Financial constraint was the most common reason given for losses to follow-up in quantitative $(32 / 33,96.9 \%)$ and qualitative $(12 / 12,100.0 \%)$ assessments. But, unavailability of means of transportation may still override the benefit that financial assistance can provide, as reported in the qualitative study. The baseline mean hemoglobin level $(8.50 \mathrm{~g} / \mathrm{dL})$, median CD4 count $\left(187.00\right.$ cells $\left./ \mathrm{mm}^{3}\right)$; median weight for height $\mathrm{z}$-score $(-0.395)$, and the median body mass index (15.40) increased significantly to respective values of $10.03 \mathrm{~g} / \mathrm{dL}, 1,030.00$ cells $/ \mathrm{mm}^{3},-0.090$, and 18.50, at 6 months ( $P$-values: 0.000 ), and $10.47 \mathrm{~g} / \mathrm{dL}, 1,203.00$ cells $/ \mathrm{mm}^{3}, 0.420$, and 19.20 , at 12 months ( $P$-values: 0.000$)$. The baseline median viral load $(45,678.00$ copies $/ \mathrm{mL})$ also decreased significantly, to 200.00 copies $/ \mathrm{mL}$ at 6 months and at 12 months ( $P$-values: 0.000 ). There was no attrition from death or loss to follow-up, and adherence to ART was $100 \%$, at 6 months and at 12 months of follow-up.

Conclusion: Through the $\mathrm{KC}$, children were retained in care, with excellent adherence to ART, and good clinical and immunoviralogical responses to ART, even after being previously lost to follow-up.

Keywords: retention-in-care, children, antiretroviral therapy, Makurdi, Nigeria

\section{Introduction}

Regional differences in the HIV burden exist in Nigeria. ${ }^{1}$ According to the National Sentinel Survey among pregnant women in antenatal care in Nigeria, Benue State (located in the North Central region) has the highest human immunodeficiency virus (HIV) prevalence rates: $10 \%$ in $2005,10.6 \%$ in 2008 , and $12.7 \%$ in $2010 .{ }^{1}$ However, with current advancement in the prevention of mother-to-child-transmission (MTCT) of HIV interventions, the MTCT risk of HIV can be reduced to between $1 \%-2 \%{ }^{2}$ Unfortunately, MTCT of HIV continues in Nigeria, because of poor uptake of available prevention of mother-to-child-transmission (PMTCT) services. ${ }^{3}$ In our own setting, the MTCT risk of HIV was as high as $34.4 \%$, in $2011 .{ }^{4}$ 
In Nigeria, like elsewhere, ${ }^{5-8}$ the provision of care and treatment for HIV-infected children is plagued with many challenges. Some of these challenges include: concerns about HIV disclosure to the child, orphanhood and vulnerability occasioned by HIV infection, lack of appropriate pediatric antiretroviral formulations, adherence to lifelong antiretroviral therapy (ART), shortage of skilled health personnel, and issues concerning retention of children in care and treatment programs. ${ }^{5-8}$

A comprehensive care and treatment package for HIV-infected children started in Benue State at the Federal Medical Centre (FMC), Makurdi, in May 2006, seven years after the commencement of the adult ART program in 1999. Since the inception of the program, there has been a progressive increase in enrollment, necessitating running a pediatric clinic twice per week (on Wednesdays and Fridays). Accompanying this surge in enrollment is the problem of retaining children in care and treatment of HIV. Although a robust, home-based care (HBC) unit was in place in the adult arm of the program, which was helpful in tracing the children with irregular clinic attendance, and those lost to follow-up, often, these children were again lost to follow-up, soon after they had been contacted and resumed clinic attendance. In realizing the problems inherent in irregular clinic attendances, including running out of antiretroviral drugs and possible suboptimal adherence to ART, and the consequent treatment failures, we developed an interventional psychosocial program, named Kiddies' Club (KC).

This study aimed to assess the impact of $\mathrm{KC}$ on ART adherence and clinic attendance among children who were previously lost to follow-up.

\section{Materials and methods}

\section{Study area and setting}

The study was conducted at the Paediatric ART Clinic of the Riverside Specialist Clinics of the FMC, Makurdi. The facility is supported by the AIDS Prevention Initiative in Nigeria and Harvard Pepfar (President's Emergency Plan for AIDS Relief) Program. The clinic provides pediatric HIV care and treatment in accordance with the 2007 and 2010 Nigerian Guidelines. ${ }^{9} 10$ Between May 2006 and December 2012 , the program had cumulatively recruited 1,101 children, of whom 749 had been initiated on highly active antiretroviral therapy (HAART). However, only 746 children (410 males, 336 females) were still receiving care, and only 588 children were still on HAART (328 males, 260 females) during this time. By June 2011, a total of 51 children on HAART had been lost to follow-up, of whom 37 were successfully traced.

\section{Ethical consideration and programmatic support}

The study was approved by the Research and Ethics Committee of the FMC, Makurdi. Caregivers (CGs) also signed a written consent for the study. We proposed the concept of the KC at the Technical Committee of the Program. After a thorough review, both financial and moral support were given toward achieving the goals and objectives of the $\mathrm{KC}$. Recruitment into the $\mathrm{KC}$ was voluntary, and it was made clear to CGs and children that those who declined to be a member of the $\mathrm{KC}$ would not have their care and treatment affected.

\section{Follow-up of HIV-infected children on HAART: operational definitions}

HIV-infected children ( $\leq 15$ years old) were seen monthly for the first 3 months, every 3 months in the first year, and every 6 months thereafter. Unscheduled visits took place at any time during care. ART was commenced in accordance with the clinical and age-dependent immunological criteria of the WHO guidelines of 2006. ${ }^{11}$ Clinical, growth, and developmental evaluations, and immunoviralogical assessments were determined at each scheduled and unscheduled visit. Treatment failures (virological, immunological, and clinical) followed the standard definitions of the WHO guidelines of $2006,{ }^{11}$ and were considered in children who had received HAART for at least 24 weeks, with ensured adherence to therapy and adequate nutrition. ${ }^{9,10} \mathrm{~A}$ maternal orphan is the child whose mother has died. A paternal orphan is the child whose father has died. A double orphan is the child whose father and mother have died.

A CG is a person who has consistently assumed responsibility for the housing, health, or safety of the child; who administers the child's medication daily, and who brings the child to clinic appointments. The CG may be a parent of the child or a biological or non-biological relation, if the child is an orphan.

Optimal adherence (95\%) was when a child missed $<3$ doses in a twice-daily regimen for 30 days. Suboptimal adherence $(<95 \%)$ was when a child missed 3 doses in a twice-daily regimen for 30 days. Full (100\%) adherence was not missing any dose within a period of 30 days. Adherence was assessed by recall from children (for those $\geq 12$ years old) and CGs (when the child was $<12$ years old).

Lost to follow-up was defined as an instance where the child was not seen for 3 consecutive months from a scheduled visit date. 
Undernutrition in children less than 5 years old was determined by the weight for height z-score (WHZ) being more than two standard deviations lower than the WHO reference median. ${ }^{12}$ For children $\geq 5$ years old, undernutrition was defined as body mass index $(\mathrm{BMI})<18.5 .^{13}$

\section{Kiddies' Club and its core activities (the intervention)}

The Kiddies' Club comprised: children who had been on HAART (for at least 6 months), who were previously lost to follow-up but were brought back into care after being traced; their caregivers; and the pediatric team. The pediatric team was multidisciplinary, including the pediatricians, the HIV counselor, the nutritionist, a social worker, and the pediatric nurses. Willingness of the $\mathrm{CG}$ to join the $\mathrm{KC}$ was the inclusion criterion. Unwilling CGs and their children were excluded from the KC. The primary objectives of the $\mathrm{KC}$ were to ensure that HIV-infected children were retained in care, with optimal adherence to HAART. Secondarily, we also expected appreciable improvement in the clinical and immunoviralogical responses of the children to HAART. Therefore, we followed-up 33 children of consecutive, consenting caregivers over 1 year (June 2011 to June 2012), and assessed the attainment of set objectives at the 6th month and 12th month. The Club met in an alternate, mixed composition of $16+1$ caregiver-child pairs, every last Saturday of every month. The monthly get-together took place within the premises of the Riverside Specialist Clinics, which had been beautifully adorned for the purpose. The routine at the monthly party is shown in Figure 1; the whole activity took an average of 6 hours. Children were given a nutritious meal, prepared from locally sourced food materials, and the opportunity was also used to demonstrate to the CGs (who were also actively involved in the cooking) how to preserve the nutrient content of the food materials by avoiding overcooking.

For preschool children ( $0-5$ years), the primary focus was the CG. The discussion was about general knowledge on HIV/AIDS, HIV disclosure, optimal adherence to lifelong ART, and what families can do to prevent the spread of HIV within the family and the general population. Practical demonstrations were given on pill-swallowing and how to attend to a child who is vomiting, refusing, or having difficulty swallowing medications. The reasons why scheduled clinic appointments are more frequent at the initiation of HAART, and why subsequent clinic attendances are also important, were discussed. CGs were encouraged to freely discuss identified barriers to regular clinic attendances,

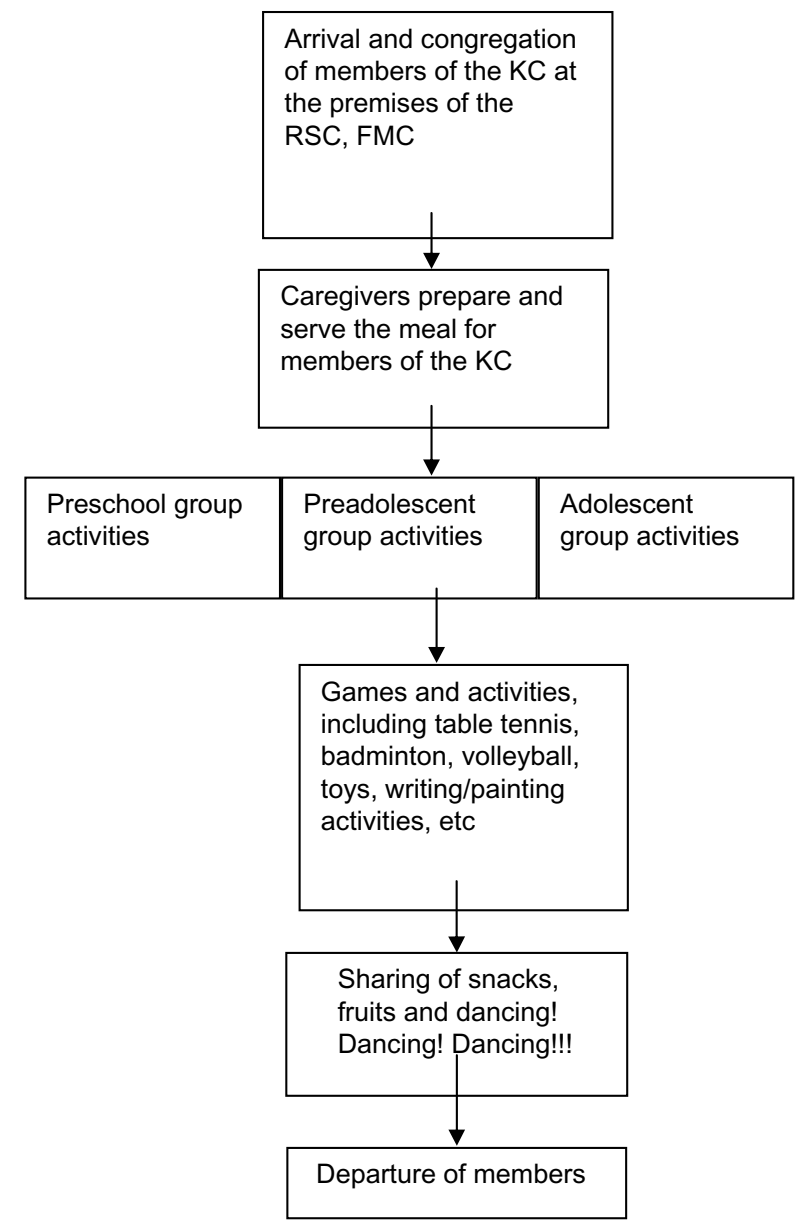

Figure I The routine at the monthly get-together party. Abbreviations: KC, Kiddies' Club; RSC, Riverside Specialist Clinic; FMC, Federal Medical Centre.

and how the program can assist to ensure retention-in-care. Examples of remedies suggested by CGs, which were applied immediately by the $\mathrm{KC}$, were: disbursement of small stipends for transportation to the clinic, and use of mobile telephone to remind CGs of the need to administer anti-retroviral (ARV) medications to the children. Children in this age group were allowed to play with toys and to explore with writing materials and small games. Through folk story, proverbs, and plays, emphases were placed on the need for $100 \%$ adherence to ARV medication and clinic attendance.

Children aged between 6-8 years old (preadolescent) were exposed to the basic concept of HIV/AIDS. They were also introduced to issues of HIV disclosure and were motivated for $100 \%$ adherence to ARV medication and clinic attendance. The children engaged in games and group activities, and were encouraged to share personal stories of their experiences of societal stigmatization and rejection, and how they were able to cope. Other activities were as described for the younger age group. 
For the adolescents (9-15 years old), messages were given on: care of the body, career talks, how to live positively with HIV (denial and fear of HIV), sex education, and the virtue of abstinence from sex before marriage. Education on the use of condoms for protection against HIV and other sexually transmitted diseases was individualized for inquisitive adolescents. In particular, adherence issues, in the face of drug fatigue, as well as how to cope with side effects of ARV drugs, were dealt with. The pediatric team engaged the adolescents on self esteem and avoidance of risky lifestyles. For adolescents who were horizontally infected, issues on transgenerational sexual activities were discussed. They were encouraged to have a social network, whereby they can call one another over the phone to remind themselves about ARV medication. Other activities were as described for the preschool children.

\section{Data collection and management}

For quantitative analyses, a structured questionnaire was used at enrollment into $\mathrm{KC}$, to capture factors that impact on retention-in-care and loss to follow-up. These include patient-related, medicine-related, and hospital-related factors. Also, nutritional status, CD4 count, viral load, treatment failures, and hemoglobin level were noted at enrollment, and subsequently at the 6th month and 12th month.

A qualitative survey was applied at the end of 12 months of follow-up, using a focused group discussion (FGD). The FGD involved twelve carefully-selected, active members of the $\mathrm{KC}$, including four CGs of the preschool children's group, four CG-child dyads of the preadolescent group, and four adolescent children. The group discussants were identified as numbers 1-12. For the preadolescent group, either the CG or the child was taken as one discussant. Three members of the pediatric team (two doctors and one nurse), who were fluent in the indigenous Tiv and Idoma languages, were involved in the FGD. The proficiency of the pediatric team was verified through roleplay and pretesting among another six child-CG dyads, who were not part of the final FGD.

Audio recording of the FGD was later translated into English. Discussions took place in the waiting space of the clinic, and lasted for 5 hours. A semi-structured format with open-ended questions was used. The questions covered three thematic areas: i) reasons for missed clinical appointments and the challenges of clinic attendance, ii) how the $\mathrm{KC}$ has impacted on clinic attendance and HAART adherence, and iii) what could be done by the program to improve retentionin-care and adherence to HAART.

\section{Statistical analysis}

For quantitative data, statistical analysis was performed using SPSS version 16 software (IBM Corporation, Armonk, NY, USA). Characteristics of the 33 children and their caregivers, at enrollment into the $\mathrm{KC}$, were summarized using means and medians (for continuous variables) and proportions (for categorical variables). Categorical variables were compared using the chi-squared test. Means at two time-points (on recruitment and at 6 months follow-up) and at three time-points (recruitment, and at 6 months and 12 months follow-up) were compared using the paired Student's $t$-test and repeated measures analysis of variance (ANOVA), respectively. The medians at two time-points and at three time-points (as for mean values) were tested using the Wilcoxon signed-rank and the Friedman tests, respectively. For all analyses, $P$-values less than 0.05 were considered statistically significant. For the FGD, the quotations included in the text best represent the range of ideas voiced around the three key themes. Anonymity of these quotes was maintained by identifying the discussant by sex and age only.

\section{Results \\ Quantitative study}

Some characteristics of the 33 children and their caregivers on recruitment into the $\mathrm{KC}$

Table 1 shows that the 33 children in the KC comprised 17 males and 16 females (ratio: 1:0.94). The median age was 5 years. No child was found to be receiving care in another health facility, and none was still receiving ART at the time of recruitment. The majority $(19 / 33,57.6 \%)$ were in the preschool age group. The predominant tribe was Tiv (30/33, 90.9\%). Onethird of the children were orphans, with a majority of double orphans $(8 / 33,24.2 \%)$. The siblings of 29 children were also HIV-infected. HIV disclosure had been done in almost half $(15 / 33,45.5 \%)$ of the 33 members. The median age at HIV diagnosis was 18 months. On recruitment, only two children were receiving second-line HAART, abacavir/lamivudine/ lopinavir-ritonavir. The median time the children had been receiving HAART was 9 months.

A few children $(6 / 33,18.2 \%)$ were responsible for the administration of their own ARV medicines. Ten children refused to take the ARV medicine. Side effects of ARV medicines had been experienced among five children. Antituberculous drugs were coadministered with HAART in three children, before they were lost to follow-up. No child believed that the hospital environment was hostile.

Table 2 shows that the majority of the CGs were mothers $(21 / 33,63.6 \%)$, followed by biological relations 
Table I Some characteristics of the 33 children on recruitment into the Kiddies' Club

\begin{tabular}{|c|c|c|}
\hline Characteristic & Number & $\%$ \\
\hline \multicolumn{3}{|l|}{ Sex } \\
\hline Male & 17 & 51.5 \\
\hline Female & 16 & 48.5 \\
\hline \multicolumn{3}{|l|}{ Age (years) } \\
\hline Median (IQR) & $5.0(3.5-8.0)$ & \\
\hline \multicolumn{3}{|l|}{ Age group (years) } \\
\hline $0-5$ & 19 & 57.6 \\
\hline $6-8$ & 7 & 21.2 \\
\hline $9-15$ & 7 & 21.2 \\
\hline \multicolumn{3}{|l|}{ Ethnicity } \\
\hline Tiv & 30 & 90.9 \\
\hline Idom & 3 & 9.1 \\
\hline \multicolumn{3}{|c|}{ Orphanhood status } \\
\hline Maternal & 2 & 6.1 \\
\hline Paternal & 2 & 6.1 \\
\hline Double & 8 & 24.2 \\
\hline Not orphan & 21 & 63.6 \\
\hline \multicolumn{3}{|c|}{ Number of other children in household } \\
\hline$\leq 4$ & 16 & 48.5 \\
\hline$>4$ & 17 & 51.5 \\
\hline \multicolumn{3}{|c|}{ Sibling also HIV-infected } \\
\hline Yes & 29 & 87.9 \\
\hline No & 4 & 12.1 \\
\hline \multicolumn{3}{|c|}{ Child knows that s/he has a chronic illness } \\
\hline Yes & 16 & 48.5 \\
\hline No & 17 & 51.5 \\
\hline \multicolumn{3}{|c|}{ Child knows that the chronic illness is } \\
\hline \multicolumn{3}{|c|}{ HIVIAIDS } \\
\hline Yes & 15 & 45.5 \\
\hline No & 18 & 54.5 \\
\hline \multicolumn{3}{|c|}{ Age of child on diagnosis of HIV (months) } \\
\hline Median (IQR) & $18.00(12.00-42.00)$ & \\
\hline$<12$ & 51 & 45.5 \\
\hline $13-24$ & 5 & 15.2 \\
\hline$>24$ & 13 & 39.4 \\
\hline \multicolumn{3}{|l|}{ Types of HAART } \\
\hline First & 31 & 93.9 \\
\hline Second & 2 & 6.1 \\
\hline \multicolumn{3}{|c|}{ Child can identify ARV drugs } \\
\hline Yes & 14 & 42.4 \\
\hline No & 19 & 57.6 \\
\hline \multicolumn{3}{|c|}{ Duration on HAART before LTFP (months) } \\
\hline Median (IQR) & $9.00(8.50-36.00)$ & \\
\hline$<12$ & 19 & 57.6 \\
\hline $13-24$ & 4 & 12.1 \\
\hline$>24$ & 10 & 30.3 \\
\hline \multicolumn{3}{|c|}{ Duration of time LTFP (days) } \\
\hline Median (IQR) & $135(127.5-160)$ & \\
\hline \multicolumn{3}{|c|}{ Child is responsible for HIV administration } \\
\hline Yes & 6 & 18.2 \\
\hline No & 27 & 81.8 \\
\hline \multicolumn{3}{|c|}{ Child still on ART at enrollment into KC } \\
\hline Yes & 0 & 0.0 \\
\hline No & 33 & 100.0 \\
\hline
\end{tabular}

Table I (Continued)

\begin{tabular}{lll}
\hline Characteristic & Number & $\%$ \\
\hline $\begin{array}{l}\text { Child had commenced ART in another } \\
\text { health facility at enrollment into KC }\end{array}$ & & \\
$\quad$ Yes & 0 & 0.0 \\
$\quad$ No & 33 & 100.0 \\
Child refused/vomited ARV at some time & & \\
$\quad$ Yes & 10 & 30.3 \\
$\quad$ No & 23 & 69.7 \\
Child experienced ARV side effects & & \\
at some time & & \\
$\quad$ Yes & 5 & 15.2 \\
$\quad$ No & 28 & 84.8 \\
Child taking other medication apart from & & \\
ARV & & 9.1 \\
$\quad$ Yes & 3 & 90.9 \\
No & 30 & \\
Child believes hospital is hostile/stigma & & 100.0 \\
$\quad$ Yes & 0 & \\
No & 33 & \\
\hline
\end{tabular}

Abbreviations: KC, Kiddies' Club; IQR, interquartile range; LTFP, loss to follow-up; ARV, antiretroviral medicine; HARRT, highly active antiretroviral therapy; ART, antiretroviral therapy.

(in six children). Overall, $84.8 \%(28 / 33)$ of the CGs were female. The median age was 37 years, with a majority being 35 years or older $(24 / 33,72.8 \%)$. Two-thirds (69.7\%) of the CGs were married. A little more than half $(51.5 \%$, 17/33) of the CGs had attained secondary education. CGs had been changed in 16 children (48. 5\%). Most CGs (26/33, 78.8\%) were also receiving HAART, and almost all the CGs $(31 / 33,93.9 \%)$ takes alcohol. Some forms of financial support had been received by almost two-thirds (20/33, 60.6\%) of the CGs, while a significant proportion $(27 / 33,81.8 \%)$ were gainfully employed. A little more than half $(17 / 33,51.5 \%)$ reached the clinic in less than 1 hour. Almost all of the CGs (32/33, 97.0\%) believed in the efficacy of HAART in providing good viralogical control. Only two CGs said that the hospital and/or health workers were hostile.

Table 3 shows the reasons for losses to follow-up. "I didn't have money" was the reason most commonly given, among 32 CGs (96.9\%); this was followed by "I forgot", among 22 CGs (66.7\%), then "I got busy" $(19,57.6 \%)$, "I traveled" $(17,51.5 \%)$. and "I felt sick" $(16,48.5 \%)$.

Table 4 shows that, overall; the mean hemoglobin level, median CD4 count, median WHZ score, and median BMI were significantly higher at 6 months and at 12 months from the recruitment time $(P=0.000)$. The median viral load also decreased significantly over the two time periods from recruitment $(P=0.000)$. However, much of the improvement in all of the variables took place 
Table 2 Some characteristics of the caregivers on recruitment into the Kiddies' Club

\begin{tabular}{|c|c|c|}
\hline Characteristic & Number & $\%$ \\
\hline \multicolumn{3}{|l|}{ Type of CG } \\
\hline Father & 4 & 12. \\
\hline Mother & 21 & 63. \\
\hline Biological relation & 6 & 18 \\
\hline Non-biological relation & 2 & 6.1 \\
\hline \multicolumn{3}{|l|}{ Sex of CG } \\
\hline Male & 5 & 15 \\
\hline Female & 28 & 84 \\
\hline \multicolumn{3}{|l|}{ Age of CG (years) } \\
\hline Median (IQR) & $37.00(33.00-44.00)$ & \\
\hline $15-24$ & 5 & 15 \\
\hline $25-34$ & 4 & 12. \\
\hline $35-39$ & 12 & 36. \\
\hline$\geq 40$ & 12 & 36 \\
\hline \multicolumn{3}{|l|}{ Marital status of CG } \\
\hline Married & 23 & 69. \\
\hline Divorced & 6 & 18 \\
\hline Widowed & 4 & 12. \\
\hline Single & 0 & 0.0 \\
\hline \multicolumn{3}{|l|}{ Educational status of CG } \\
\hline None & 6 & 18. \\
\hline Primary & 3 & 9.1 \\
\hline Secondary & 17 & 51. \\
\hline Tertiary & 7 & 21 \\
\hline \multicolumn{3}{|l|}{ Has had more than one CG } \\
\hline Yes & 16 & 48. \\
\hline No & 17 & 51. \\
\hline \multicolumn{3}{|l|}{ CG on HAART } \\
\hline Yes & 26 & 78. \\
\hline No & 7 & 21 \\
\hline \multicolumn{3}{|l|}{ CG drinks alcohol } \\
\hline Yes & 31 & 93. \\
\hline No & 2 & 6.1 \\
\hline \multicolumn{3}{|l|}{ CG takes Indian hemp } \\
\hline Yes & 4 & 12. \\
\hline No & 29 & 87. \\
\hline \multicolumn{3}{|c|}{ CG receives financial support } \\
\hline Yes & 13 & 39. \\
\hline No & 20 & 60. \\
\hline \multicolumn{3}{|l|}{ CG uses memory aids } \\
\hline Yes & 2 & 6.1 \\
\hline No & 31 & 93. \\
\hline \multicolumn{3}{|l|}{ Employment status of CG } \\
\hline Unemployed & 6 & 18 \\
\hline Employed & 27 & 81. \\
\hline \multicolumn{3}{|c|}{ CG has disclosed HIV to the child } \\
\hline Yes & 14 & 42. \\
\hline No & 19 & 57. \\
\hline \multicolumn{3}{|c|}{ Time spent in getting to the clinic } \\
\hline Yes ( $\geq I$ hour $)$ & 16 & 48 \\
\hline No $(<$ I hour $)$ & 17 & 51. \\
\hline \multicolumn{3}{|c|}{ CG believes in efficacy of HAART } \\
\hline Yes & 32 & 97. \\
\hline No & 1 & 3.0 \\
\hline \multicolumn{3}{|c|}{ CG believes hospital is hostile/stigma } \\
\hline Yes & 2 & 6.1 \\
\hline No & 31 & 93. \\
\hline
\end{tabular}

Abbreviations: CG, caregiver; IQR, interquartile range; HARRT, highly active antiretroviral therapy.
Table 3 Reasons for losses to follow-up on recruitment into the Kiddies' Club

\begin{tabular}{lll}
\hline Reason & Number & $\%$ \\
\hline "I didn't have money" & 32 & 96.9 \\
Yes & 1 & 3.1 \\
No & & \\
"I forgot" & 22 & 66.7 \\
$\quad$ Yes & 11 & 33.3 \\
No & & \\
"I got busy" & 19 & 57.6 \\
Yes & 4 & 42.4 \\
No & & \\
"I traveled" & 17 & 51.5 \\
Yes & 16 & 48.5 \\
No & & \\
"I felt sick" & 16 & 48.5 \\
Yes & 17 & 51.5 \\
$\quad$ No & & \\
CG just died & 3 & 9.1 \\
Yes & 30 & 90.9 \\
$\quad$ No & & \\
"I had visitors at home and I couldn't & & 9.1 \\
leave them" & 3 & 90.9 \\
Yes & 30 & \\
No & & \\
Abbreviation: CG, Caregiver. & &
\end{tabular}

between the recruitment point and 6 months of follow-up. Although not statistically significant, the general trend was that the proportion of children with hemoglobin level $\geq 10 \mathrm{~g} / \mathrm{dL}, \mathrm{CD} 4$ count $\geq 200$ cells $/ \mathrm{mm}^{3}$, undetectable viral load of $<200$ copies $/ \mathrm{mL}$, WHZ scores $>-2$ standard deviation, and $\mathrm{BMI} \geq 18.5$ increased over time (at 6 months and at 12 months). Also, although not statistically significant, there was a drop-off in the proportion of children with viralogical and immunological failures at 6 months and at 12 months.

39.4 For clinical failure, a significant drop-off occurred in the proportion of children with clinical failure between recruitment and at 6 months of follow-up $(P=0.019)$. A dramatic improvement occurred in the observed adherence to HAART, as all 33 subjects reported a $100 \%$ adherence at 6 months and at 12 months.

One child (9.1\%) was hospitalized, at about 6 months of follow-up, for severe lobar pneumonia; he spent 5 days in admission, but was well enough to join his peers for the monthly KC. There was no attrition from deaths or loss to follow-up among the 33 children over the 12 months of follow-up.
97.0

3.0

6.1 93.9

\section{.}

(1)




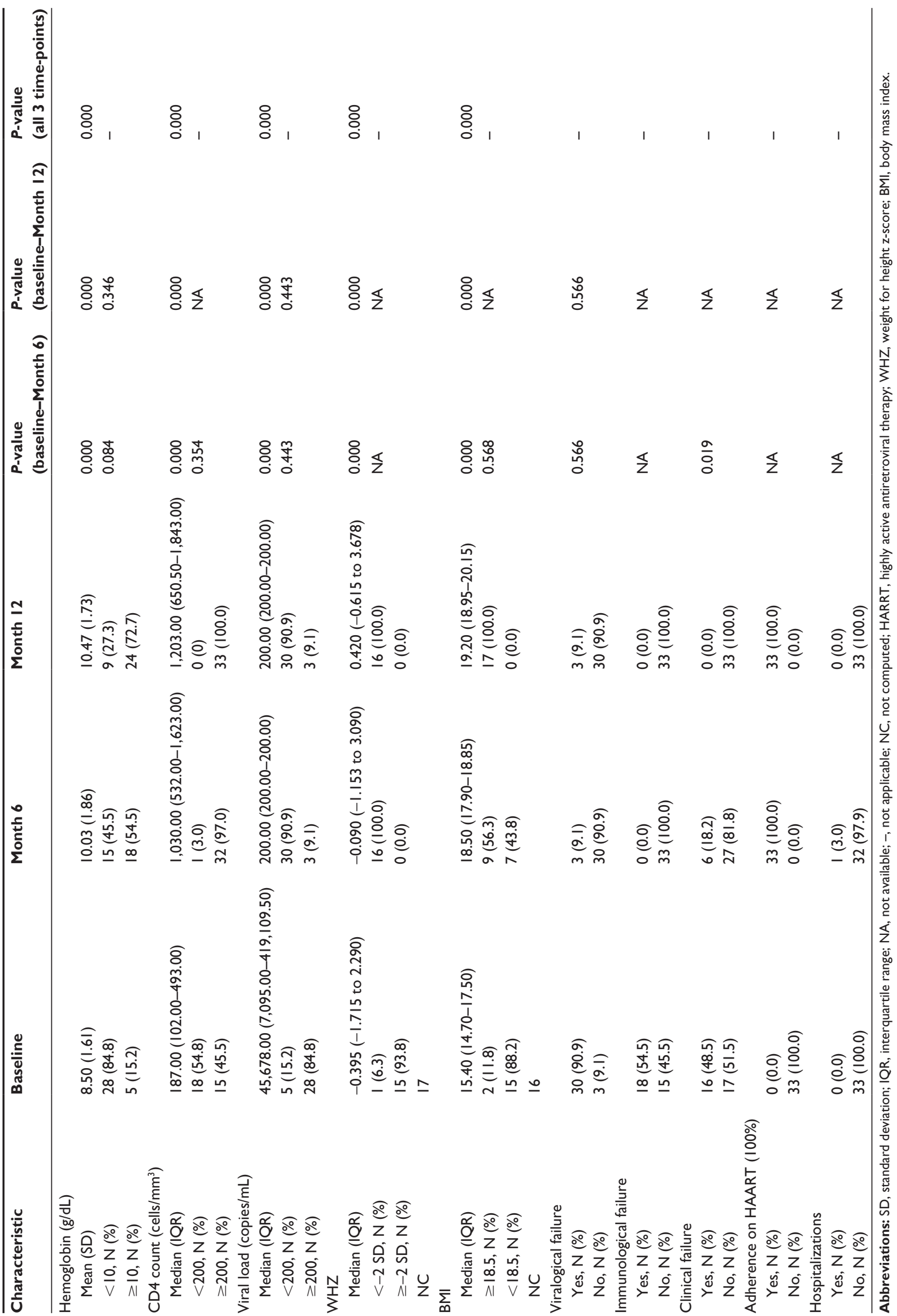




\section{Reasons for missed clinic appointments} and the challenges of clinic attendance

Again, financial constraint was the most common barrier to regular clinic attendance, reported by all the discussants $(12 / 12,100 \%)$. Engagement in farming, at the beginning of the rainy season, was another reason, given by 11 discussants. A major barrier also identified was frequent hospital visits for pharmacy refill early in the initiation phase of ART. Other reasons included: the issue of a long distance from the home to the clinic. Occasionally, the clinic date coincides with a "market day". Another obstacle identified by discussants was difficulty in getting transportation to the clinic, for those living at difficult-to-reach villages.

Discussant 8, a 39 year old man, captured most of these reasons when he said:

Yes, before the stipends, money is the major issue, I struggle to feed my family, I struggle to pay my children's school fees, at the end of the day, there is little money left for me to transport myself and my four children to the hospital, every month [...]. At the beginning of the rain, I have to choose between coming to the clinic and clearing the farm land [...]. During the harvest period, I also have to assist my wife in selling the farm produce. There is often a lot of conflict at the clinic time.

Discussant 7, a 37 year old woman said:

My village is far from Makurdi, but I would not like to access treatment at the nearby health facility because I don't want my friends and relations to see me [...]. But coming to Makurdi is not easy either, because once you missed the vehicle, you can no longer leave the village for that day, this is a big problem, not only in clinic attendance for ARV medicines, a lot of people bitten by snakes have died as a result of not getting a vehicle to convey the victims to the hospitals where the antidote (anti-snake venom) is available.

\section{How the $\mathrm{KC}$ has impacted on clinic attendances/HAART adherence}

All twelve discussants agreed that they have never missed the clinics since they joined the KC. They also concurred that they now know that HIV infection is no longer "a death sentence", but a chronic disease that can be managed and lived with. All the female members of the FGD said they have learnt for the first time how not to overcook vegetables, and how to combine various locally-available foods to make a balanced nutritious diet. All the eight children said they had made new friends, and they were always happy to come to the clinic. The pill-swallowing lessons were found to be very helpful, as they had learnt how to swallow the tablets whole, thereby avoiding the unpleasant taste of the medication. They also agreed that when they dance, they forget their worries, but they also dance to remember to take their medication. The four adolescents said they could freely discuss the issue of disclosure with their relations, as they no longer felt constrained not to do so.

Discussant 5, a 7-year old boy in the preadolescent group, captured all the feelings of the $\mathrm{KC}$, when he said:

Dancing, eating, and having fun make us remember to take our medication, and we always want to come back to the clinic.

Discussant 12, a 28 year old woman, said:

The HIV infection has turned into a blessing for me. Shortly when I joined the $\mathrm{KC}$, I learnt a lot about cooking, which I never knew before. This emboldened me to start a small scale restaurant in my village. In a short while, all the villagers preferred to buy food from me. I don't put Maggi (a common commercial soup condiment) in my soup, yet the taste of the locust beans is irresistible. My restaurant is also special because I am the only one that served fruits when people buy other foods.

Discussant 11, a 42 year old woman, said:

When I see other children, I know I am not alone with this problem of HIV. This sort of encouraging me, because I know that remembering to give my child the ARV medicine is a sure way of keeping him healthy enough to play with his peers.

Discussant 9, a 43 year old man, said:

We thank the program for the stipends they now give to us for transportation fares. This has solved the major problem we used to have. I am convinced in my heart that the programmers have our interest at heart [...] even if they now stop giving us the stipends, I will strive on my own by all means to get money for transportation.

\section{What could be done by the program to improve retention-in-care and adherence to HAART}

All discussants expressed hope that the $\mathrm{KC}$ would continue, so that other children with similar challenges could benefit from the program. They also agreed that lengthening out the clinic appointments would ensure a regular clinic attendance and retention-in-care (once in 6 months, regardless of whether 
ART is just being started or not). They suggested that members of the HBC unit should accompany the children home, on recruitment, so that contact tracing may be easier, as the home addresses they gave verbally on recruitment were often not traceable. They opined that the program should make arrangement to start tracing the defaulters once a clinic appointment is missed. They suggested that the idea of a memory aid, through the sending of text messages to families with mobile telephones, should be extended to all children in the ART program.

Discussant 4, a 27 year old man, said:

We hope this KC would not come to an end soon. Personally, I have benefited immensely from it and I wish that other families would also benefit from it. If I had known that the clinic visits would thin out with time, I would have endured. Now, I only bring my child every 6 months. I think the programmers should give more time to educate parents on this fact.

Discussant 12, a 28 year old woman, said:

I know it may pose additional cost on the program, but I think if the program can be sending text messages to all the patients on ARV to remind them of their medication, that would be helpful, but my concern is that most parents are uneducated and may not be able to read these text messages, or they may now forget when they don't receive the text messages.

Discussant 3 , a 35 year old man, said:

To my own mind, I think the programmer should start looking for clinic defaulters once they missed one clinic appointment, and not wait before tracing them. I am sure by doing this a lot of losses to follow-up would be avoided.

\section{Discussion}

The study has shown that, through the $\mathrm{KC}$, children were retained in care, with an excellent adherence to ART, and good clinical and immunoviralogical responses to ART were obtained at 6 months and 12 months of follow-up.

Financial constraint was the reason most commonly given, in both quantitative and qualitative assessments, for missed clinic appointments. Similar observations were reported in Uganda, Malawi, Cambodia, India, and Kenya, among adult populations on ART. ${ }^{14-18}$ However, provision of transport fares for CGs alone may not fix this problem. As Discussant 7 rightly noted, in most instances, unavailability of means of transportation may override the benefit that financial assistance can provide. In most rural Nigerian settings, vehicular traffic in the villages is very low, because of the bad roads, and a missed opportunity to board the few available commercial vehicles means that clinic attendance may not be possible for that day. Bangsberg et al have earlier made a similar observation. ${ }^{19}$

Engagements in farming at the beginning of the rainy season, and choosing between clinic attendance and the need to pursue other financially-rewarding commitments are other identified barriers to clinic attendances. Thus, this study underlines the fact that in Nigeria, like other resource-limited settings, accessing health care is often just one need within a nexus of other urgent, competing priorities. ${ }^{14}$

Interestingly, the frequent hospital visits necessary for pharmacy refill in the early phase of ART were also identified as a reason for not attending the clinic, in the qualitative study. This underscores the need to give detailed information about the treatment protocol to the caregivers at the pre-ART preparatory phase. Jaffar et al also reported that by reducing follow-up visits to health facilities, better achievement of retention-in-care was gained..$^{20}$

Long distances between the CGs homes and the clinic were also a reason identified for missing follow-up appointments. Others have also identified the same. ${ }^{21}$ However, efforts at decentralizing accessibility of ART services, in the classic "Hub and Spokes" model, may not readily fix this challenge. In our qualitative study, we found out that stigmatization and lack of social support may explain the reason why CGs may not take up ART services at decentralized health facility sites that may be nearer to their homes.

During the FGD, CGs suggested that lengthening out the clinic appointments (ie, once in 6 months) would ensure a regular clinic attendance and retention-in-care. They opined that programmers should know (by following them home) the home addresses of the CGs of the children needing HAART, so that defaulters may be easier to trace, as the home addresses they give verbally on recruitment are often not traceable. They also suggested the idea of a memory aid, through the sending of short text messages to families. All of these suggestions from the CGs, and lots more, had been summarized earlier by Harries et al in their ten key interventions, aiming at retaining HIV/AIDS patient in care. ${ }^{22}$

The positive findings of this study were strengthened by the following facts. Firstly, the $\mathrm{KC}$ was, from the outset, an interventional program aiming at retention-in-care of children who were lost to follow-up. Secondly, when we realized that financial constraint was the commonest barrier to a regular clinic attendance, our program quickly made available some 
stipends, to cushion this challenge. Thirdly, we also made use of memory aids, via text messaging, to remind children and CGs of the need to take ARV medicines. Fourthly, through the efforts of a well-organized HBC unit, we were able to follow-up members of the $\mathrm{KC}$ to their homes, where further emphasis was placed on the need for $100 \%$ adherence to HAART.

However, we are cautious in the generalization of our findings, as substantial socioeconomic and geographic differences exist in many African-based treatment programs, which may make the application of a similar $\mathrm{KC}$ difficult. Also, we may argue that the $100 \%$ adherence on ART, recalled by the CGs and children during the follow-up at the $\mathrm{KC}$, was due to social desirability and recall bias. This assumption should be judged against proven improvement in the clinical and immunoviralogical responses to ART. Furthermore, whilst the application of a KC may be possible for a cohort that is not doing well in clinic attendance, it definitely may not be financially feasible to apply a $\mathrm{KC}$ to all children being recruited into an ART program. On the other hand, we cannot totally rule out a possibility of children and CGs intentionally defaulting on follow-up appointments so that, eventually, they may be recruited into $\mathrm{KC}$ and thus enjoy all the benefits they have heard so much about. The sustainability of an interventional program like $\mathrm{KC}$ is also often not predictable, as implementing partners can withdraw support at short notice.

\section{Conclusion}

The study has shown that, through the $\mathrm{KC}$, children were retained in care, with an excellent adherence to ART and good clinical and immunoviralogical responses to ART. Therefore, we strongly recommend the $\mathrm{KC}$ for other pediatric ART programs that may be facing similar challenges as exist in our setting.

\section{Acknowledgments}

We wish to acknowledge Dr Jonah Abah, the Principal Investigator, and all the members of the Technical Committee of the AIDS Prevention Initiative in Nigeria/Harvard Pepfar program, at Federal Medical Centre, Makurdi, for the moral and financial support given to the Kiddies' Club. We also acknowledge the following people, who are members of the Kiddies' Club, but who did not meet the authorship criteria. They include: Mrs Yemisi Lim and Mrs Felicia Edigah (Pediatric Nurses), Mrs Helen Akuete (HIV Counselor), Mrs Rose A Chamber (Nutritionist), and Elder Damko (Social Worker). We must also thank all the 33 children of the Kiddies' Club and their caregivers, without whom this report would not have been possible.

\section{Disclosure}

The authors declare no conflicts of interest in this work.

\section{References}

1. Federal Ministry of Health. ANC HIV Sentinel Survey. Abuja, Nigeria: Federal Ministry of Health; 2010.

2. Malyuta R, Newell ML, Ostergren M, Thorne C, Zhilka N. Prevention of mother-to-child transmission of HIV infection: Ukraine experience to date. Eur J Public Health. 2006;16(2):123-127.

3. National Agency for the Control of AIDS. Fact Sheet: PMTCT in Nigeria. Abuja, Nigeria: NACA; 2012.

4. Anígilájé EA, Dabit OJ, Ageda B, Hwande S, Bitto TT. The prevalence and predictors of HIV infection among children of mothers who missed prevention of mother to child transmission of HIV interventions in Makurdi, Nigeria. J AIDS Clin Res. 2013;4(11): 1000249.

5. Meyers T, Moultrie H, Naidoo K, Cotton M, Eley B, Sherman G. Challenges to pediatric HIV care and treatment in South Africa. J Infect Dis. 2007;196 Suppl 3:S474-S481.

6. Mothi SN, Karpagam S, Swamy VHT, Mamatha ML, Sarvode SM. Paediatric HIV - trends and challenges. Indian J Med Res. 2011;134(6): 912-919.

7. Rwemisisi J, Wolff B, Coutinho A, Grosskurth H, Whitworth J. 'What if they ask how I got it?' Dilemmas of disclosing parental HIV status and testing children for HIV in Uganda. Health Policy Plan. 2008;23(1):36-42.

8. Wasti SP, Simkhada P, Randall J, van Teijlingen E. Issues and challenges of HIV/AIDS prevention and treatment programme in Nepal. Global $J$ Health Sci. 2009;1(2):62-72.

9. Federal Ministry of Health. National guidelines for paediatric HIV and AIDS treatment and care. Abuja, Nigeria: Federal Ministry of Health; 2007.

10. Federal Ministry of Health. National guidelines for paediatric HIV and AIDS treatment and care. Abuja, Nigeria: Federal Ministry of Health; 2010.

11. World Health Organization. Antiretroviral therapy of HIV infection in infants and children: towards universal access. Geneva, Switzerland: WHO; 2006.

12. World Health Organization. WHO Anthro for personal computers, version 3.2.2, 2011: Software for assessing the growth and development of the world's children, Child growth standards. Geneva, Switzerland: WHO; 2011.

13. World Health Organization. Physical status: the use and interpretation of anthropometry. Report of a WHO Expert Committee. WHO Technical Report Series 854. Geneva, Switzerland: WHO; 1995.

14. Geng IH, Bangsberg DR, Musinguzi N, et al. Understanding reasons for and outcomes of patients lost to follow-up in antiretroviral therapy programs in Africa through a sampling-based approach. $J$ Acquir Immune Defic Syndr. 2010;53(3):405-411.

15. Yu JK, Chen SC, Wang KY, et al. True outcomes for patients on antiretroviral therapy who are "lost to follow-up" in Malawi. Bull World Health Organ. 2007;85(7):550-554.

16. Raguenaud ME, Isaakidis P, Vonthanak S, et al. Good ART patient outcomes and survival achieved in a six-year HIV/AIDS program in Cambodia. Proceedings of the 5th IAS Conference on HIV Pathogenesis, Treatment, and Prevention; July 19-22, 2009; Cape Town, South Africa; 2009.

17. Joshi K, Jhanwar S, Mathur A, et al. Barriers in adherence of ART (anti retroviral treatment): an experience of ART Centre of Western Rajasthan, India. Proceedings of the 17th International AIDS Conference; August 3-8, 2008; Mexico City, Mexico; 2008. 
18. Ochieng-Ooko V, Ochieng D, Sidle JE, et al. Influence of gender on loss to follow-up in a large HIV treatment programme in western Kenya. Bull World Health Organ. 2010;88(9):681-688.

19. Bangsberg DR, Ware N, Simoni JM. Adherence without access to antiretroviral therapy in sub-Saharan Africa? AIDS. 2006;20(1):140-141.

20. Jaffar S, Amuron B, Foster S, et al. Rates of virological failure in patients treated in a home-based versus a facility-based HIV-care model in Jinja, southeast Uganda: a cluster-randomised equivalence trial. Lancet. 2009;374(9707):2080-2089.
21. Rabkin M, Austin J, Nash D, et al. High patient retention rates in a multinational HIV/AIDS treatment program: The Columbia University Mother-to-Child-Plus Experience. Proceedings of the 17th Conference on Retroviruses and Opportunistic Infections; February 16-19, 2010; San Francisco, Califonia; 2010.

22. Harries AD, Zachariah R, Lawn SD, Rosen S. Strategies to improve patient retention on antiretroviral therapy in sub-Saharan Africa. Trop Med Int Health. 2010;15 Suppl 1:70-75.

\section{Publish your work in this journal}

HIV/AIDS - Research and Palliative Care is an international, peerreviewed open-access journal focusing on advances in research in HIV, its clinical progression and management options including antivira treatment, palliative care and public healthcare policies to contro viral spread. The journal welcomes original research, basic science, clinical \& epidemiological studies, reviews \& evaluations, expert opinion \& commentary, case reports \& extended reports. The manuscript management system is completely online and includes a very quick and fair peer-review system. Visit http://www.dovepress.com/ testimonials.php to read real quotes from published authors.

Submit your manuscript here: http://www.dovepress.com/hivaids---research-and-palliative-care-journal 